Old Dominion University

ODU Digital Commons

2000

\title{
Measurements of Salinity in the Coastal Ocean: A Review of Requirements and Technologies
}

\author{
Catherine Woody \\ Eddie Shih \\ Jerry Miller \\ Thomas Royer \\ Old Dominion University, royer@ccpo.odu.edu \\ Larry P. Atkinson \\ Old Dominion University, latkinso@odu.ed
}

See next page for additional authors

Follow this and additional works at: https://digitalcommons.odu.edu/ccpo_pubs

Part of the Fresh Water Studies Commons, and the Oceanography Commons

\section{Original Publication Citation}

Woody, C., Shih, E., Miller, J., Royer, T., Atkinson, L. P., \& Moody, R. S. (2000). Measurements of salinity in the coastal ocean: A review of requirements and technologies. Marine Technology Society Journal, 34(2), 26-33.

This Article is brought to you for free and open access by the Center for Coastal Physical Oceanography at ODU Digital Commons. It has been accepted for inclusion in CCPO Publications by an authorized administrator of ODU Digital Commons. For more information, please contact digitalcommons@odu.edu. 
Authors

Catherine Woody, Eddie Shih, Jerry Miller, Thomas Royer, Larry P. Atkinson, and Richard S. Moody 


Catherine Woody
National Data Buoy Center
National Oceanic and
Atmospheric
Administration
Stennis Space Center, MS
Eddie Shih
Coast Survey Development
Lab
National Oceanic and
Atmospheric
Administration
Silver Spring, MD
Jerry Miller
Oceanography Division
Naval Research Laboratory
Stennis Space Center, MS
Thomas Royer, Larry P.
Atkinson, and Richard
S. Moody
Center for Coastal Physical
Oceanography
Old Dominion University
Norfolk, VA

\section{ABSTRACT}

Salinity, a measure of the dissolved salts in seawater, is a fundamental property of seawater and basic to understanding biological and physical processes in coastal waters. In the open ocean long term salinity measurements are identified as necessary to understand global climate studies, hydrological cycle, and circulation. In the coastal oceans, information on salinity is critical to understanding biological effects on ecosystem function such as disease, nursery grounds, or harmful algal blooms and on physical processes such as freshwater runoff, estuarine mixing, and coastal currents. While the importance of salinity is recognized, little attention has been given to making routine measurements as to the location and frequency of such measurements. These issues were addressed in a workshop concerned with salinity measurements in coastal oceans, requirements for such, and measurement technology.

\section{INTRODUCTION}

$\mathbf{T}_{\mathrm{s}}^{\mathrm{h}}$ The importance of salinity time series measurements in understanding coastal ocean processes has been long recognized. Unfortunately, the number of sites where salinity is routinely measured has decreased considerably in the past years. Salinity measurements are made routinely at very few places, and there is no logical plan for where salinity measurements should be made or how frequently.

To address the immediate national needs for salinity measurements in the coastal ocean, a workshop was held September 14-15, 1998, in Hampton, Virginia. The goals of the workshop were to:

- Establish acceptable techniques based on needed accuracy and cost-efficiency.

- Establish criteria for location and frequency of salinity measurements.

- Inventory all existing coastal salinity measurements.

- Identify users of coastal salinity and derivative data (density, stratification, coastal currents, etc.).

- Determine requirements (ie. anti-fouling) to be addressed by new technology. Twenty-eight experts drawn from an interdisciplinary cross-section of private industry, government, and academia convened to address these issues. A review of salinity measurement requirements for US coastal waters as well as technical and programmatic recommendations for meeting them were formulated by consensus. The results of the workshop are presented in this paper.

The following section outlines the many reasons why salinity information is required. It is followed by sections that briefly describe the history of salinity measurement techniques as well as present and future technologies. Issues surrounding anti-fouling strategies are discussed in detail. Finally, criteria for salinity measurement strategies are described and recommendations for immediate implementation are summarized. Throughout the text, concensus statements agreed upon during the workshop are highlighted.

\section{WHY SALINITY?}

Qalinity has always been recognized as important in the high latitude and coastal regions, but the interest of the science community in measurements of salinity has varied from one decade to another and from one region to another. A recent workshop sponsored by the National Science Foundation on "Advances and Primary Research Opportunities in Physical Oceanography" (Royer and Young, 1999) identified global salinity measurements as one of several goals. Longtime series measurements were also identified as important to climate studies. While the community has concentrated on global heat flux measurements such as those in the World Oceanographic Circulation Experiment (WOCE) program, much less attention has been devoted to the salt budget. The vast majority of global precipitation occurs over the ocean, so knowledge of sea surface salinity could lead to better estimation of the global hydrological cycle and a better understanding of the most important greenhouse gas, water vapor.

Significant salinity changes occur at decadal time scales. For example, in the past decade some oceanic regions have experienced a decline in salinity and accompanying changes in the mixed layer depth. This is particularly true for the North Pacific where the mixed layer depth at Ocean Station P (50 N, $145 \mathrm{~W})$ has decreased at a rate of about $63 \mathrm{~m} /$ century (Freeland, et al., 1997). Elsewhere in the coastal North Pacific, the mixed layer depth has been decreasing at a rate of about $32 \mathrm{~m} /$ century. The coastal salinity as measured at Canadian lighthouse stations is decreasing at rates that vary from 1 to about 0.5 per century. However, at one location, the sea surface salinity has decreased about one in the last five years. 
To understand coastal processes, salinity and temperature of coastal waters are two fundamental parameters that must be measured, each providing different clues as to the processes at work in the system. Temperature provides information related to heat exchange, while salinity provides information about movement and dilution of waters in the coastal ocean. When integrated, temperature and salinity are indicators of transport, mixing, stratification, and frontal boundaries. Thus, salinity gives us unique and easily acquired information about issues of great importance to the coastal ocean.

Because salinity is conservative, it is a good indicator of global warming, changes in circulation, and air/sea interaction. These, however, are harder to detect in coastal waters due to the wide range of salinity and annual variability in precipitation/runoff. In fact, the need for salinity measurements in coastal oceans is quite varied, and, it was agreed by the workshop attendees, there were not enough long-term salinity measurements to adequately address the problems. It is well known that runoff from land is changing in many areas, and salinity will change. This will no doubt have significant effects on all aspects of coastal waters.

Many processes that have significant socio-economic impacts depend critically on salinity. These include but are not limited to biological effects on ecosystem function (e.g., oyster disease, nursery grounds, coastal wetlands, corals), development of harmful algal blooms (i.e., salinity as a habitat barrier), survival of invasive species (e.g., via discharged ballast water), and aquaculture (e.g., site selection as a function of salinity variability).

In addition to such biological considerations, many purely physical processes depend on salinity. For instance, changes in fresh water runoff from land affects many physical aspects (e.g., strength of estuarine and coastal currents, oceanic mixed layer depth, stratification, buoyancy fluxes, internal wave regime, air-sea gas exchange, and steric sea level). Such processes can cause problems such as movement of estuarine salt wedges that, in turn, can alter sediment deposition patterns and hence dredging requirements. Further, through its effect on water density, salinity can also affect a ship's draft and therefore its commercial load capacity. Salinity is also the key to understanding the implications of dam construction/destruction for coastal and estuarine regions.

The effects of salinity variations extend to the global scale as well. There are direct implications for the earth's heat cycle, oceanic circulation, atmospheric circulation (via indirect influence on El Nino processes), sea level, and the hydrological cycle (most notable in coastal regions where rivers bring fresh water to a focal point).

\section{Statement of Importance of Salinity Measurements}

Because of its large dynamic range in the coastal ocean, salinity is a critical variable for understanding and predicting biological and physical processes and their interactions with the food web, climate, weather, and commerce. In estuaries, salinity becomes important for drinking water intakes and agriculture activities.

\section{HISTORY}

$\mathbf{T}$ The saltiness of ocean waters has been recognized throughout recorded history.

Through the 17th and 18th centuries, investigations of salt in the ocean focused on the measurement of those salts. Georg Forchhammer (1865) introduced the term 'salinity' and determined 27 elements in sea water. He also introduced the concept that while salinity in the open ocean might vary, the ratios of the various salts to each other would remain the same. The work of William Dittmar (1884) in his analysis of 77 samples from the Challenger expedition further established the idea of 'constancy of composition,' and this provided the basis for the various methods of salinity measurement based on chemical titration techniques employed through the mid-20th century. Typical precision was generally better than \pm 0.02 (Emery and Thomson, 1998).

The determination of salinity from measurements of conductivity was first recognized by Knudsen (1901) but was not developed until the $1950 \mathrm{~s}$. At that time, a conductivity salinometer was developed for the International Ice Patrol that was capable of measuring salinity to better than 0.01 (Emery and Thomson, 1998). The instrument contained six thermostatically controlled conductivity cells and reached a precision of 0.003 (Cox, 1963). In addition to the higher precision afforded by conductivity determinations of salinity, conductivity measurements offered the potential of rapid, accurate profiling of the water column rather than only obtaining a few tens of discrete bottle samples. The first salinity-temperature-depth (STD) profiler used conductivity cells that had problems with fouling (Hamon, 1995). However, a STD with an inductive cell was soon developed that avoided the electrode fouling problem (Hamon and Brown, 1958). Problems with salinity 'spiking' due to a mismatch of temperature and conductivity sensor response times and controversy over the algorithm used to calculate salinity soon led to the return of the mea- 
surement of conductivity-temperature-depth (pressure) (CTD) by modern instruments. These instruments have a precision of better than 0.005 . Table 1 lists the progression of salinity measurements.

In concert with the higher precision of salinity determination, new definitions have been developed for the determination of salinity directly from conductivity (Lewis, 1980). The Practical Salinity Scale (PSS-78) definition is based on the ratio of the conductivity of the sample to the conductivity of standard seawater of 35. It is a practical scale in that it is removed from the original definition of salinity that is based on the salt content of the water sample (Knudsen, et al., 1902).

Although the modern definitions of salinity from conductivity assume constancy of composition in the open ocean, that assumption is violated in coastal waters. The precision required for coastal salinity measurements is much less than that required for the open ocean because the variability of salinity in the coastal ocean is relatively large in both time and space. Therefore, less precise methods of measurement may be used. For example, salinities were frequently determined from density measurements using hydrometers and temperatures. This was done at coastal locations such as lighthouses around the United States and Canada and continues to be done at Canadian lighthouses. The accuracy is of the order of \pm 0.2 . The difficulty in measuring salinity, compared to temperature measurements, has resulted in a dearth of salinity measurements, sometimes inaccurate and sometimes using unproven techniques. The latter was true in the 1970 s with the introduction of STDs. It promised detailed vertical profiling that was impossible with discrete bottle sampling. As it often turned out, there were many samples per depth, but their accuracies were much less than those obtained with bottles and salinometers. As a result, much hydrographic data using STDs and early CTDs from that era are suspect.

Table 1. Chronology of Significant Instrumentation and Techniques for the Measurement of Salinity

Knudsen titration of chlorides Conductivity-type salinometer Index of refraction Sea Going electrode in situ Inductive-type salinometer Sea going bench salinometer STD (inductive) in situ CTD (conductive) in situ CTD (conductive) in situ AUTOSAL laboratory Index of refraction
The difficulty in taking salinity measurements frequently prohibits their incorporation in ocean sampling schemes. For example, upper layer thermal structure has been measured for decades using mechanical bathythermographs (BT) or expendible bathythermographs (XBT) and even aircraft deployed XBTs (AXBT). These temperature measurements have routinely been taken from merchant vessels and military platforms. The military interest is not necessarily in the temperature structure but rather in the distribution of sound speed in the upper ocean layers for submarine detection. However since salinity does not affect sound velocity to a great extent in the open ocean, it was not necessary to include it. So, we have decades of temperature measurements over the global ocean taken by many different organizations, but global salinity measurements have generally only been made from research vessels. Now that the Navy is more keenly interested in coastal regions, the importance of the effect of salinity on sound speed has been recognized. So that we might begin to survey global sea surface salinity, simpler techniques, such as the XBT for temperature, are needed to measure salinity from ships of opportunity or through remote sensing.

\section{PRESENT TECHNOLOGY FOR SALINITY MEASUREMENTS}

$\mathbf{T}$ loday, salinity is routinely measured in two ways. The first and more traditional method is through collection of water with bottles and analyses done with a laboratory salinometer. While this method is considered the most accurate and precise, it is the most time consuming and labor intensive. The second is by direct in situ CTD measurements. CTD sensors are presently used routinely in the field for surveying and monitoring. This is done using a profiling CTD or moored in situ conductivitytemperature (CT) sensor. Some are partially calibrated electronically in the laboratory, but ultimately all are put in a temperature controlled salt water bath and calibrated with bottle samples/laboratory salinometers or with a higher accuracy conductivity sensor.

Salinity values can range from near zero to 45 in coastal areas, but the present salinity definition only covers a range of 2 to 42 . Most CTs could cover the wider range with an expanded salinity definition.

The attendees posed the following questions regarding sensor technology:

- What are the characteristics of the salinity sensor?

- What is a reasonable length of time between servicing? 
- What is acceptable for drift, precision and accuracy?

The consensus statement on salinity measurement technology was:

\section{Statement on need for accuracy}

For coastal waters with a high variance in salinity, the workshop participants agreed that the desired short-term goal for an in situ salinity sensor is to be capable of measuring salinity to 0.1 accuracy and maintain stability for a minimum of 6 months. It is to be portable, low cost, low power, and non-fouling. The long-term goal is to improve the accuracy to 0.01 with a range of values between 0.1 and 42 .

\section{ANTI-FOULING TECHNIQUES AND ISSUES}

Tn situ sensors in coastal waters suffer from Lbiological fouling that degrade sensor accuracy. Antifoulant paints, while effective for varying time scales, may alter the geometry through degradation of the paint itself. An accuracy of 0.1 is attainable for short deployments (weeks), but, even with the best anti-fouling techniques, accuracy degrades to worse than 1.0 for deployments of several months.
Tri-butyltin (TBT) is the most effective antifoulant material. However, because of its toxicity, TBT has strict environmental controls for permitting its use. Some states will allow limited use of TBT with strict guidelines. With antifoulant treatment, salinity sensors presently can operate for up to 3 months in coastal waters and 2.5 years in deep water before severe accuracy degradation occurs.

There are few studies available on antifoulants and their effects on sensors and data. One such study was conducted in the Netherlands to select a suitable sensor to measure conductivity and temperature for continuous, in situ monitoring of coastal waters (van Oort, et al., 1998). Upon selection of the sensor, further studies were conducted on the effects of three different antifoulant paints on the sensor. Bondit $\mathrm{B} 2 / \mathrm{C} 6$ (based on ammonium hydroxide), Seajet 033 (30-60\% cupricoxide and 10-30\% xylene), and Jotun HSE 3410 (0-1\% tri-butyltin and 30-60\% cupricoxide) were used, with one sensor free of antifoulant used for visual comparison only. The field tests were conducted in brackish, somewhat stagnant water. The results of the tests are shown in Figure 1. Conductivity data were recorded from the three test cases with reference conductivity measured weekly using a hand-held sensor. The results showed Jotun HSE 3412 to be the most effective, and it was

Figure 1. Test results for antifoulants used on selected temperature/conductivity sensors.

\section{Antifoulingtest $G$ en $T$ \\ Bruinisse, 27-06 t/m 12-09-97}

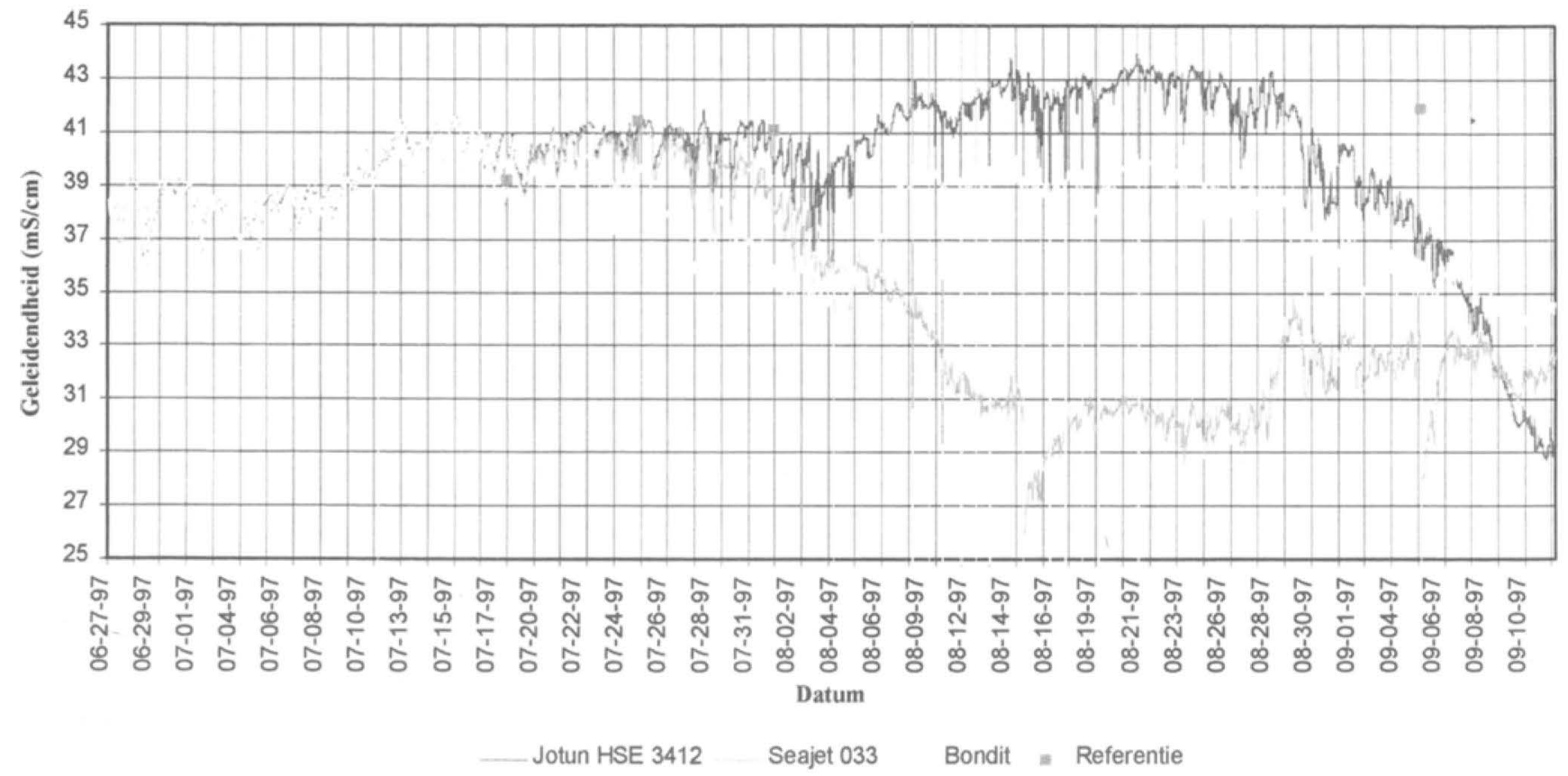

MTS Journal • Vol. 34, No. 2 • 29 
found that the use of antifoulant paint increased the maintenance-free period for about a week.

The authors did not feel that this time increase was enough to justify the use of the antifoulant for open ocean or coastal water.

The following issues and questions were presented for further investigation:

- There is presently no known review for antifoulants and their effectiveness.

- How do we prevent fouling?

- What are the legal issues of using TBT, and what recommendations should be made?

- Where should research and development focus-on new technology or environmentally safe and effective antifoulants?

- A clearinghouse on bio-fouling of sensors needs to be established.

\section{Statement on Needs in Anti-fouling:}

It is presently desired to deploy sensors to accurately collect data for six months with a long-term goal of one year. Improved anti-fouling technology needs to be devel- oped to successfully complete long term, in situ salinity measurements without harming the environment.

\section{FUTURE TECHNOLOGY- REMOTE SENSING}

$\mathbf{R}$ emote sensing offers a solution to the fouling problem but presents technological challenges. Such technology is now available for research and development but is a long way from routine use. It is estimated that in 5 to 10 years, an instrument may be available for routine measurements.

Images of coastal and estuarine surface salinity have been produced using L-Band microwave signals remotely sensed from aircraft. An airborne swath-scanning surface salinity mapper (Miller et al., 1998) has been flown successfully in several coastal environments along the east coast of the United States (Figure 2). For typical sampling scenarios, salinity noise levels are a few tenths for $1 \times 1 \mathrm{~km}$ pixels. The next generation of this instrument has already

Figure 2. Microwave sensing of sea surface salinity.

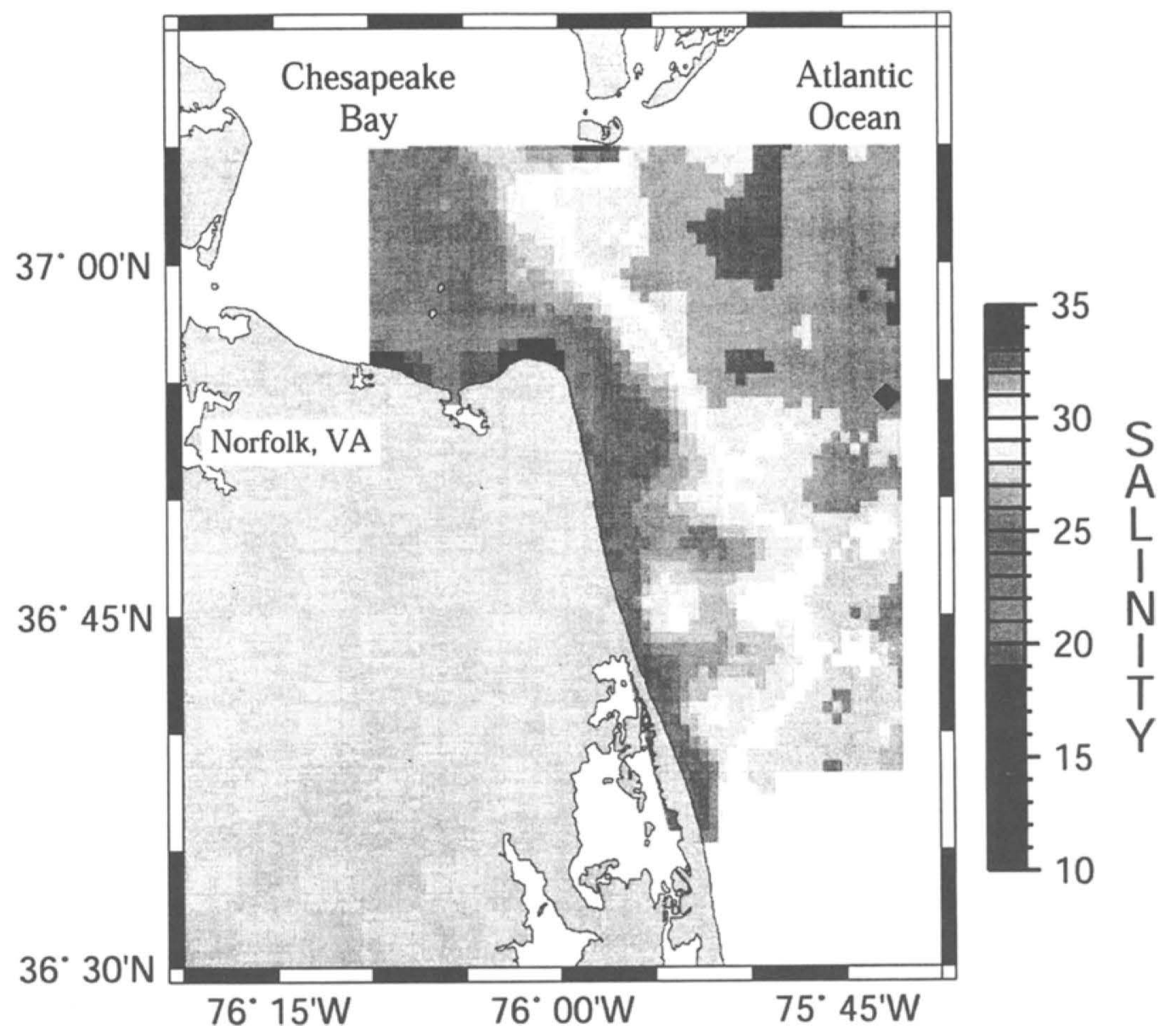


been designed and components tested.

Expected noise levels will approach 0.1 for single 1 -second realizations and less for $1 \times 1 \mathrm{~km}$ pixel averages. This new remote sensing capability provides a means of substantially advancing our understanding of physical processes in the coastal zone where traditional moored and shipbased observations are compromised due to the prevailing short temporal and spatial scales. Salinity images have been generated for the tropical waters of Florida Bay and for the temperate Chesapeake Bay under a variety of atmospheric and hydrologic forcing conditions. These data reveal local flow regimes and provide the basis for diagnostic calculation of associated low-frequency velocity fields. When combined with other data (e.g., ocean color, radar-derived surface currents, suspended sediments), details of linear and non-linear biogeophysical processes can be addressed.

Implementation of this technology on satellites for global imaging of salinity is possible. Beyond salinity, this technology can be used to estimate soil moisture and to map the extent of sea ice and oil spills. Existing airborne instruments are being used as test-beds for satellite engineering studies. They also constitute the basis for development of simple, inexpensive sensors which can be mounted on buoys and other available coastal and estuarine platforms. Deployed in the air, these will be naturally free of fouling.

\section{Statement on Needs in Remote Sensing Technology}

Once operational, remote sensing will provide a cost effective mechanism to map surface salinity to aid in understanding coastal processes.

\section{CRITERIA FOR SALINITY MEASUREMENTS}

ue to the large variability in coastal and
estuarine waters, the following questions were posed concerning the location for measurements:

- What should the criteria for salinity observations be for coastal waters?

- What are the models that require salinity measurements and what locations for salinity measurements are needed to satisfy those needs?

Major features such as coastal currents, plumes from estuaries and rivers, and critical habitats were listed as important criteria for deciding the location of measurements. Large scale sampling may be required to identify the boundaries of such features and to monitor variability. Length scales for along-shore and cross-shelf need to be defined.
While a monitoring system cannot be expected to provide detailed coverage of salinity structure throughout the coastal ocean, it should be capable of revealing large-scale and qualitative changes in coastal salinity conditions. Spatial distribution of salinity sensors should be such that cross-shelf and along-shore variability of coastal currents which transport larvae, nutrients, and contaminants is qualitatively indexed. To achieve such coverage, one should deploy sensors a few baroclinic Rossby radii offshore as well as within one radius of shore. As for along-shore spacing, the larger salinitydriven coastal currents (i.e., those most likely to significantly affect resources) have alongshore scales of one to a few hundred kilometers. A nominal spacing of $100 \mathrm{~km}$ is a reasonable target. Actual along shore spacing should be tailored to local conditions and isobaths.

Numerical models complement field measurements in many ways. They provide information and forecasting capability over a wide area, predicting environmental conditions where observations are not available, as well as a better understanding of the physical phenomena in estuarine and coastal waters. Numerical models also guide field measurement planning. Coastal and estuarine nowcast/forecast models consist of the laterally or vertically integrated two-dimensional (2-D) or threedimensional (3-D), time-dependent, numerical hydrodynamic momentum equations, the continuity equation, and embedded equations of mass transport (e.g., salinity and temperature). The water density gradient induces gravitational circulation and affects the vertical mixing processes. Density is related to the salinity and temperature through the equation of state. Output fields of water level, currents, salinity, and temperature are important input parameters to tide and current forecasts plus water quality, biological, and ecosystem models. For large ocean models, salinity is also an important parameter in determining mixed layer properties and dynamic height for velocity calculations. Salinity measurements used in estuarine and coastal nowcast/forecast models provide initial conditions, boundary conditions, model verification, and model improvement. In the data assimilation process, salinity data are used to improve initial conditions.

The capability of reproducing the longterm salinity trends has been demonstrated (Wang, Johnson, and Cerco, 1998, and Schmalz, et al., 1994). Presently, many model simulations are made using salinity fields constructed by spatial and temporal interpolations of sparsely distributed historical data sets. For example, typical discrepancies between model simulation results and measurements for a Chesapeake Bay year-long simulation are in the order of 
$10 \%$ in the main bay and $15-20 \%$ in the tributaries (Johnson, et al., 1991), and 1-4 (PSS) RMS differences for a Galveston Bay simulation (Schmalz, 1996). Major sources of errors include lack of adequate and accurate salinity inputs and freshwater inflows and a lack of understanding of vertical mixing processes. Long-term, reliable, and adequate spatial distributions of salinity data are badly needed. Table 2 identifies the information needed for model input.

In models developed by the National Oceanic and Atmospheric Administration (NOAA), salinity, temperature, currents, and other hydrodynamic parameters are computed at different spatial resolutions. The grid spacing is dependent on the particular estuary or coastal area. Generally, a model grid of $10 \mathrm{~km}$ near the coast and $20 \mathrm{~km}$ offshore is used for coastal models. A 3 to $10 \mathrm{~km}$ grid was used in Chesapeake Bay, and a $250 \mathrm{~m}$ to $3.5 \mathrm{~km}$ grid in Galveston/Houston Bay with a finer grid of 60 $\mathrm{m}$ to $1.3 \mathrm{~km}$ in shipping channels. In the New York/New Jersey Harbor a spacing of 50 to 750 $\mathrm{m}$ and finer were used for modeling. Underway towed salinity and temperature profiling systems have been useful in obtaining ocean boundary data with moored or CTD cast measurements to establish climatology. Real-time salinity data are presently being collected at a limited number of existing NOAA PORTS sites operated by the National Ocean Service (NOS) and at some Coastal Marine Automated Network (C-MAN) stations operated by the National Data buoy Center (NDBC).

\section{LOCATIONS OF SALINITY MEASUREMENTS}

Both during and after the workshop, the comB munity was surveyed to determine where and by whom salinity measurements are currently being made. A comprehensive list of sites

Table 2. Desired model input.

\begin{tabular}{ll}
\hline Location & $\begin{array}{l}\text { Sampling range from river inflows to shelf boundaries (100-200 } \\
\text { km offshore) }\end{array}$ \\
Spatial Distribution & $\begin{array}{l}\text { Horizontal to include salinity gradients seaward and downstream } \\
\text { end of tributaries } \\
\text { Vertical to include surface, halocline, and bottom }\end{array}$ \\
Temporal Distribution & $\begin{array}{l}\text { Long-Time Series through discrete, profiling, or in situ sampling } \\
\text { with an accuracy of } 0.01 \text { covering daily, seasonal, and annual } \\
\text { variability }\end{array}$ \\
Sampling Frequency & $\begin{array}{l}\text { Hourly } \\
\text { boundary conditions in some model simulations) }\end{array}$ \\
Data Quality & $\begin{array}{l}\text { Uniform methodology and format to assure reliable data collection } \\
\text { with known uncertainty bounds }\end{array}$
\end{tabular}

* CT data are currently sampled at 6-minute intervals as currents and water levels at NOS automated Physical Oceanographic Real-Time Systems (PORTS) stations. This sampling interval is desirable for PORTS application modeling. was compiled and is available as part of the workshop report which is available online at http://www.ccpo.odu.edu/salthtml.htm. Briefly, the federal government supports salinity measurements near five major harbors through NOAA/NOS's PORTS system plus other locations operated by NOAA/NDBC. The NOAA/NOS Status and Trends program collects salinity data at 120 stations but only once per year. Eleven coastal states and three universities also collect salinity data either regularly or occasionally. The National Association of Marine Laboratories has documented 73 labs which collect salinity data and make it available on the web. However, like the Status and Trends program, many of these are short-duration efforts with limited temporal and spatial coverage.

\section{CONCLUSIONS AND RECOMMENDATIONS}

Qalinity is an important, fundamental property of seawater in the coastal zone.

Salinity:

- Directly affects biological and physical processes.

- Serves as an inexpensive, easily measured proxy for more expensively detected pollutants (tracking sewage outfall plumes, excessive estuarine and river outflow).

- Provides critical information on processes related to ecosystem function and human impacts.

- Can be measured easily and economically with routine maintenance and calibration.

While it was determined that salinity should be measured at locations to provide insight into regional processes such as river plumes and coastal currents, it is necessary to consider ease of maintenance and instrument stability and survivability. Further development of in situ and remote measurement techniques is required to address these constraints.

Recommendation:

- Establish regional working groups to determine standard measurement locations for salinity

- Continue development of remote sensing techniques for mapping of surface salinity

Platforms of opportunity such as NOS PORTS sites, NDBC C-MAN and coastal buoys, and the Corps of Engineers (COE) remote terminal units are logical locations for salinity measurements. They are located in bays, estuaries, harbors, near coastal waters, and on the shelf. All of these are remote stations with telemetered data. States such as Texas and Washington maintain coastal and estuarine stations and thus provide platforms for salinity measurements. 
Recommendation:

- Establish a government working group to make salinity a standard measurement from national networks for environmental monitoring

Fouling is a fundamental technical challenge in making salinity measurements. Both the technical challenge of finding effective antifouling materials and the regulator issues related to using these materials need coordinated assistance and possible state and federal legislative assistance.

Recommendations:

- Conduct studies on antifoulants to include effectiveness, legal issues, environmental safety

- Establish a clearinghouse for biofouling of sensors

The workshop recommends the creation of a nationally recognized effort to coordinate monitoring of salinity at specific locations along the United States coastline. The coordination would provide the following:

- Information on technical issues such as fouling

- Comparative information on sensor systems

- Coordination of calibration

- Information on and location of available data

- Framework and testbed for sensor development

- Development of archiving scheme for data at NODC

Guided by these recommendations and a coordinated effort we can develop the infrastructure and framework required for meeting the nation's requirements for salinity information.

\section{ACKNOWLEDGMENTS}

Thanks to Kim McCoy, Ocean Sensors, Inc., for providing Table 1. Ms. Carole Blett provided logistical support for the work shop. The National Ocean Data Buoy Center provided partial support for the workshop.

\section{REFERENCES}

Berger, R.C., McAdory, R.T., Martin, W.D., and Schmidt, J.H. 1995. Houston-Galveston navigation channels, Texas project. Report 3, Three-dimensional hydrodynamic model verification. U.S. Army Corps of Engineers, Waterway Experiment Station, Technical Report HL-92-7

Bergman, T. 1784. Physical and chemical essays (translated by Edmund Cullen) Murray, London, 2 vol.

Birch, T. (ed.). 1965. The works of Robert Boyle. Georg Olms, Hildeschiem, 6 vol.

Boyle, R. 1693. An account of the honourable Robert Boyle $=\mathrm{s}$ way of examining waters as to freshness and saltness. Phil. Trans. Roy. Soc. Lond.

$17: 627-641$.
Cox, C.A.. 1963. The salinity problem. Progress in Oceanography, 1, 243-261

Dittmar, W. 1884. Physics and Chemistry, Rept. Scient. Res. H.M.S. Challenger 1873-76. 1. 251 pp.

Emery, W.J. and R.E. Thomson. 1998. Data Analysis Methods in Physical Oceanography. Pergamon Press, New York, 634 pp.

Freeland, H., K. Denman, C.S. Wong, F. Whitney, and R. Jacques. 1997. Evidence of change in the winter mixed layer in the Northeast Pacific Ocean, DeepSea Res. 44: 2117-2129.

Gay-Lussac, J.L.. 1717. Supplement a la note sur la salute de la mer, imprimee dans le sixieme volume des Annales de Chimie et de Physique. Ann. Chim. Phys. Ser. 2.7.79-83.

Hamon, B.V. 1955. A temperature-salinity-depth recorder. Conseil Permanent International pour le Exploration de la Mer. Journal de Conseil. 21:22-73.

Hamon, B.V. and N.L. Brown. 1958. A temperaturechlorinity-depth recorder for use at sea. J. Scientific Instru. 35:452-458.

Johnson, B.H., Heath, R.E., Hsieh, B.B., and Kim, K.W., and Butler, H.L. 1991. Development and verification of a three-dimensional numerical hydrodynamic, salinity, and temperature model of Chesapeake Bay. V. 1, U.S. Army Corps of Engineers, Waterway Experiment Station, Technical Report HL-91-7

Knudsen, M. 1901. Report 2ed Conf. Int. Explor. Mer, Kristiania, 1901, 38 pp.

Knudsen, M., C. Forch and S.P.L. Sorensen. 1902. Bericht uber die chemische und physikalische Untersuchung des Seewassers und die Aufstellung der neuen hydrograohischen Tabellen Wiss. Meeresunters, n.f. 6:13-184.

Lavoisier, A. 1772. Memoire sur l'usage de esprit-devin dans l'analyse des eaux minerales, Mem. Acad. Roy. Sci.(Paris), 1772, 555-563.

Lewis, E.L. 1980. The practical salinity scale 1978 and its antecedents. J. Oceanic Engineering. 5:3-8.

Miller, J.L., M.A. Goodberlet, and J.B. Zaitzeff. 1998. Airborne salinity mapper makes debut in coastal zone. EOS, Trans., Amer. Geophys. Union, 79(14):173-177.

Murray, J. 1818. An analysis of sea water; with observations on the analysis of salt brines. Trans. Roy. Soc. Edinb. 8:205-244.

Royer, T. and W. Young. 1999. The Future of Physical Oceanography. National Science Foundation. 178 pp.

Schmalz, R.A. 1996. National Ocean Service Partnership: DGPS-supported hydro survey, water level measurement, and modeling of Galveston Bay. NOAA technical Report NOS OES 012

Schmalz, R.A., Devine, M.F., Richardson, P.H. 1994 Residual circulation and thermohaline structure. Summary report, V. 2, Long Island Sound Oceanography Project, NOAA Technical Report NOS OES 003 van Oort, R.C., J.J.C. van Spronsen and P. Vergurgh. 1998. Monitoring instruments for conductivity and temperature, Werkdocument RIKZ-98.009, $20 \mathrm{pp}$.

Wallace, W.J. 1980. The development of marine chemistry until 1900. In Oceanography: The Past, M. Sears and D. Merriman, Eds., Springer-Verlag, New York. 337343 .

Wang, H.V., Johnson, B.H. and Cerco, C.F. 1998. The Chesapeake Bay experience. Proc. Estuarine and Coastal Modeling conference. 16-25 